\title{
Four-point bending tests to study the so-called plasticity effect on the residual stress results determined by the hole-drilling and ring-core methods.
}

\author{
David von Mirbach ${ }^{1,}$ a \\ ${ }^{1}$ Materials Testing Institute (MPA), University of Stuttgart, Pfaffenwaldring 32, 70569 Stuttgart, \\ Germany \\ adavid.von.mirbach@mpa.uni-stuttgart.de
}

Keywords: residual stress, hole drilling method, ring core method, differential method, experimental validation, method of adaptive calibration function

\begin{abstract}
The hole-drilling method (HDM) and ring core method (RCM) are limited to low residual stresses under $60 \%$ of the yield stress. This issue will experimentally analyze the method of adaptive calculation function, presented by the author on the ICRS9. With a four-point-bending test machine, a defined stress can be triggered between the middle bending. In this defined loading area, the strains in two load cases with the HDM and the RCM configuration were measured. With these measured strains the residual stress calculation will be analysed.
\end{abstract}

\section{Introduction}

Following studies will analyse the influence of plastification caused by the notch effect of the hole or ring core, which leads to plastification around and on the bottom of the hole and ring shaped groove already at stresses well below the yield stress of the material. With a four-point-bending test a defined homogeneous state of stress in an area with the HDM and the RCM configuration where analysed. The residual stress calculation using the integral method [1], the differential method [4] and using the differential method supplemented by the method of adaptive calibration function [5] at high residual stresses are presented. Calibration functions have to be adapted to every depth step iterative to the stress type and the residual stresses will be again calculated with the adapted functions until the right one to the type of stress and material property is found.

\section{Test set-up}

The four-point-bending test may produce a homogeneous state of stress in a defined area of a specimen. At the Materials Testing Institute (MPA) of the University of Stuttgart the four point bending test equipment was installed in a $1 \mathrm{MN}$ testing press from the company Mohr \& Federhaff AG (Mannheim). With this modified testing press, the four-point-bending specimen with a thickness of $t=30 \mathrm{~mm}$, a width of $b=150 \mathrm{~mm}$ and a length of $l=1200 \mathrm{~mm}$ could be tested. Over a length of $500 \mathrm{~mm}$ (application area) a defined homogeneous mono-axial state of stress was generated. The force $\mathrm{F}$ was measured by a weighing cell of the test press. With this force $\mathrm{F}$, the momentum $\mathrm{M}$ over the specimen could be calculated. A sketch of the four-point-bending test set-up is shown on the left side in figure 1. On the right side the flow curves of the analysed material austenitic 1.4571 and ferrite S355J2 in lateral and longitudinal direction of the four point bending specimen are documented. The flow curve was determined by tensile tests. Between the middle bearings (application area) there is a constant momentum level over a length of $500 \mathrm{~mm}$. In this "application-area" there is a homogeneous state of stress. Costly and complex strain gauge applications are installed in this area to get a defined strain over the hole or rather ring core depth. With two load cases a defined differential state of stress can be adjusted. The measuring system was an "ESAM Traveller Series Data Acquisition System" with 128 channels. To get the holes, for the HDM, the material was removed using the high-speed drilling equipment by Vishay MicroMeasurements. The tungsten carbide cutter is driven by a high-speed air turbine with approximately $300000 \mathrm{rpm}$ so that the material is removed in a brittle state. 

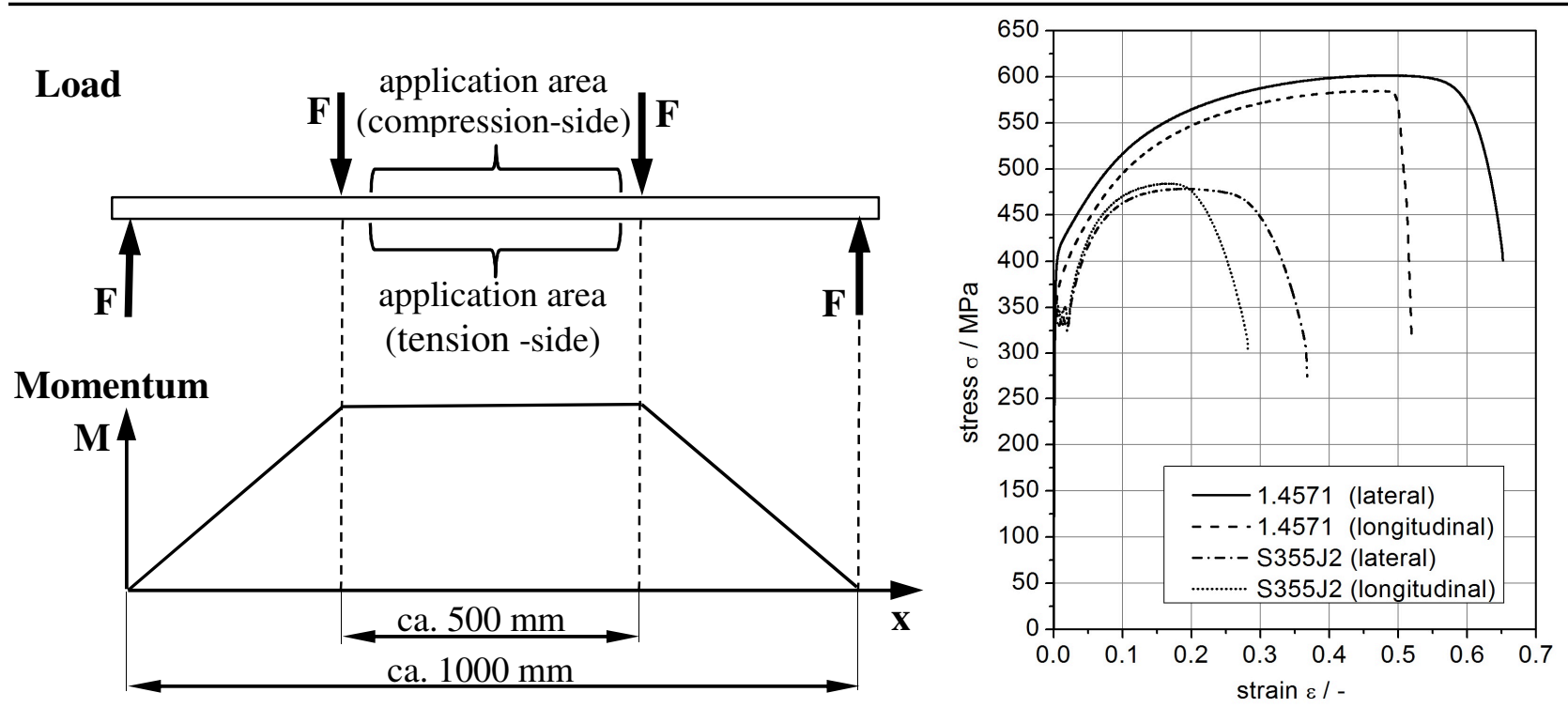

Fig. 1: Sketch and Momentum level of the four point bending test set-up (left) and the flow curve determined by tensile tests (right).

The holes have a diameter of about $\mathrm{D}_{0}=1,77 \pm 0,03 \mathrm{~mm}$. The analysed special strain gauge rosette type is CEA-XX-062UM-120 from Vishay Micro-Measurements too. Material removal of the ring slot (RCM) was performed by using spark erosion. The selected spark erosion energy was so low, that in process thermal yielding residual stresses are excluded. The solute ring cores has core diameters of $D_{0}=13,77 \pm 0,22 \mathrm{~mm}$ and a ring slot of approx. $1 \mathrm{~mm}$. The analysed special strain gauge rosette type for the RCM is RY51 from Hottinger Baldwin Messtechnik GmbH (HBM). With a dial indicator the true hole and ring-core depth was measured after installation. The specimens 1 and 3 were made of austenitic alloy 1.4571 and the specimens 2 and 4 were made of ferritic alloy S355J2. Before installation the specimen was stress relieved. The "application area" of the specimen is pictured in the map of the application area figure 2. On the tension side the points of measurement have the marking " $Z$ " and on the compression side the marking "D". All holes and ring slots were installed before testing. To measure the strains and calculate the homogeneous state of stress over the application area, on both sides five opposite linear strain gauges in longitudinal direction of the specimen were installed.

Specimen 1 and 2 (HDM) - CEA-XX-062UM-120

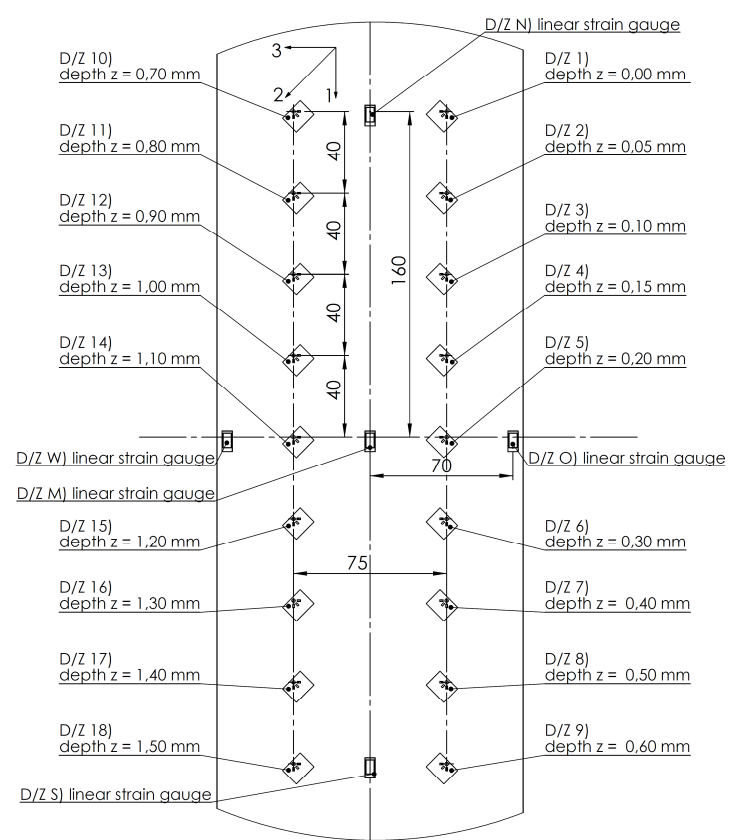

Specimen 3 and 4 (RCM) - RY51

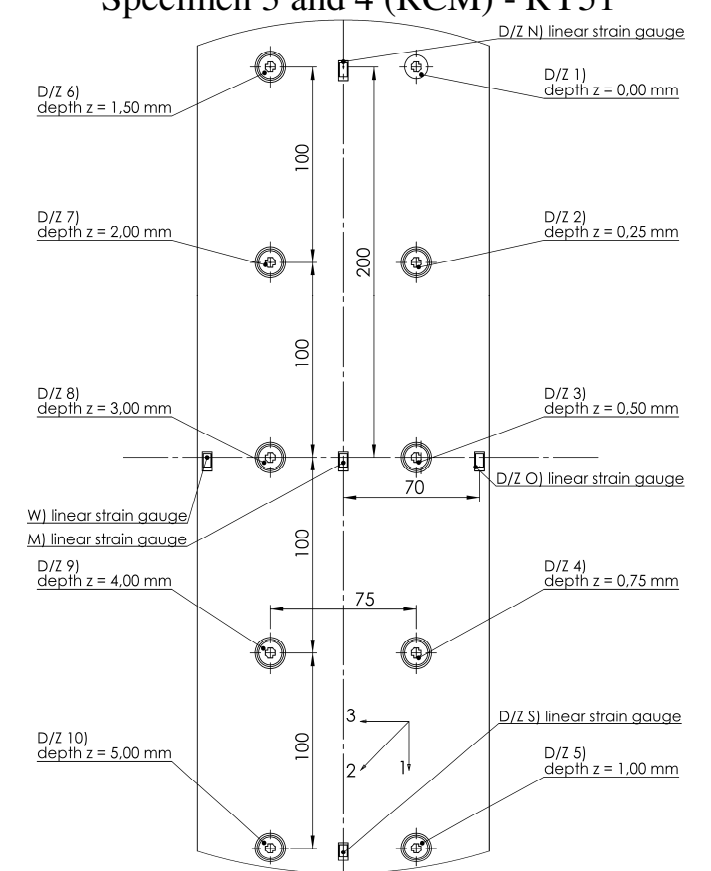

Fig. 2: Map of the application area (D compression-side; $\mathrm{Z}$ tension-side; 1 longitudinal; 3 lateral). 
The strain gauges on the tension side have the marking $Z$ _M_1, Z_N_1, Z_O_1, Z_S_1 and Z_W_1. On the compression side the oppositely linear strain gauges have the marking D_M_1, D_N_1, D_W_1, D_S_1 and D_O_1. Eighteen special strain gauge rosettes were installed on both sides of specimen 1 and 2 (HDM) with holes of different depths. The positions, (position number i) and the hole depth $\mathrm{z}$ is shown on the left side of the map of the application area. With these holes of different depths, it is possible to get the method-typical strain over the hole depth. The distance between the measuring positions is sufficiently dimensioned, so that there is no influence from one measuring position to another [4]. On the right side of the map of the application area, specimen 3 and $4(\mathrm{RCM})$ with the position number $\mathrm{i}$ and the ring-core depth $\mathrm{z}$ is pictured. Ten special strain gauge rosettes were installed on the compression side and opposite ten on the tension side with different ring-core depths. The distance between the measuring positions is sufficiently dimensioned, that there is no influence from one measuring position to another [4]. The reference depths are shown on the map of the application area.

\section{Experimental results}

The four-point-bending specimens were cyclically loaded and relieved. On the left-hand diagrams in figures 3,5,7 and 9 the strain of the middle linear strain gauge (Z_M_1) of the tension side over the momentum is documented. For the following results only the load relieving between the two black points is relevant. Influences of residual stresses in the specimen are unimportant, because they are much lower than the stresses at the lower measuring positions. Over the whole application area the specimen is relaxed between the loading points homogeneously. The differential stress between the middle bearings (application area) is uniform. So, at all measuring positions an equal definite differential stress was existent. To use geometric analogies of strain gauge rosettes, the normalized depth $\xi=z / D_{0}$ is introduced $\left(\mathrm{z}=\right.$ depth; $\mathrm{D}_{0}=$ drill diameter). The differential strain between the black loading points can be calculated with the deviations. So the strain over the hole depth or rather ring core depth can be calculated. On the middle and right-hand diagrams of figures 3, 5, 7 and 9 the strain over the hole depth or rather ring-core depth are documented. The dashed lines in these diagrams are polygon functions second grade which approximate the measured data. The stresses shown on the diagrams of figures $4,6,8$ and 10 were calculated using these polygon functions. The solid lines (integral method) present the residual stresses calculated by the integral method, the other solid lines (el. cal.) represent the residual stresses calculated by the differential method with elastic calibration functions and the dashed lines (id. pl. cal.) with the method of adaptive calibration functions. These calibration functions with elastic-ideal plastic material properties are documented in [5]. The used calculation yield stress of the austenitic alloy 1.4571 was $\mathrm{R}_{\mathrm{p} 0,2}=345 \mathrm{MPa}$ and the used yield stress of the ferritic alloy $\mathrm{S} 355 \mathrm{~J} 2$ was $\mathrm{R}_{\mathrm{p} 0,2}=325 \mathrm{MPa}$.

$$
\begin{array}{ll}
\left.d \sigma_{\text {longitudinal }}(\xi)=\frac{d M}{I} \cdot\left(\frac{t}{2}-z\right)\right) \text { and } & d \sigma_{\text {lateral }}(\xi)=0 \\
I \quad \text { The moment of inertia }\left[\mathrm{mm}^{4}\right] & M=\frac{1}{2} \cdot F \cdot 250 \mathrm{~mm} \quad \text { [6] momentum [Nm] }
\end{array}
$$

With the linear strain gauges in longitudinal direction the stresses can be calculated using equation (1) [6]. These reference stresses (measured stresses) are shown in the diagrams too.

\section{Discussion and future prospects}

Analysis of differential loads, especially the load relieving is a realistic study case for the validation of destructive residual stress analysis methods. Only elastic strains are reversible. So, relaxed global strains of the load relieving are purely elastic. Plastic strains can occur, caused by stress concentration near the hole $[2,3,5]$. The differential stress between the middle bearings is uniform. A homogenous mono-axial state of stress was observed in the application area of the specimen. 

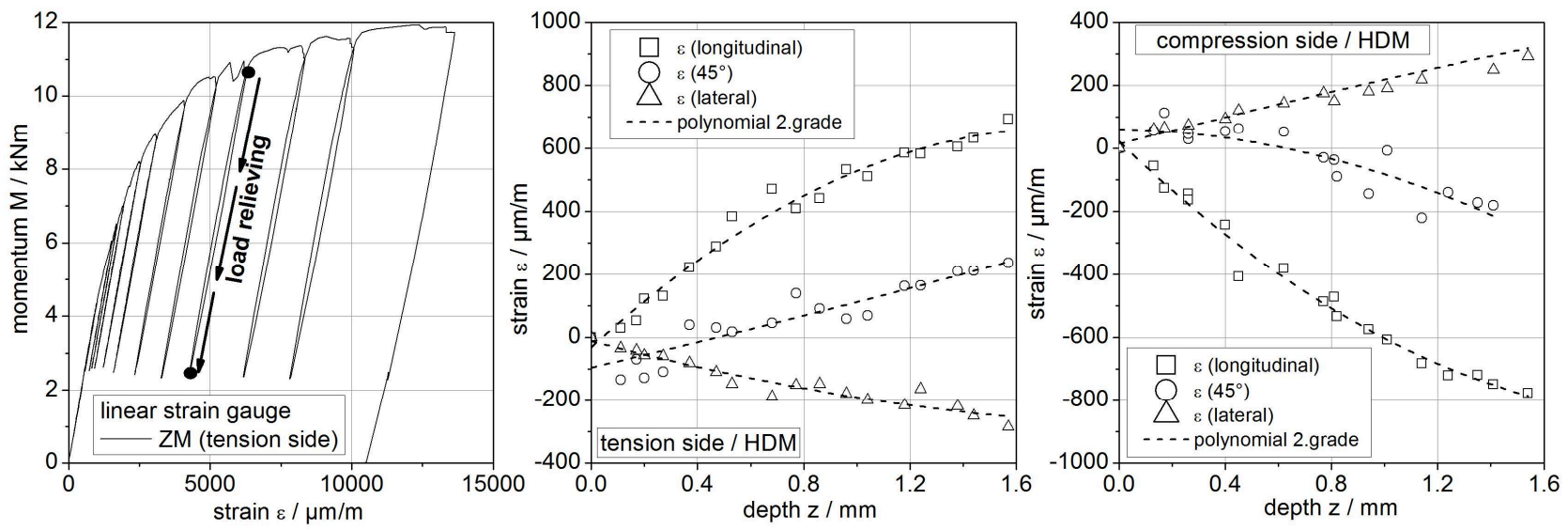

Fig. 3: Loading of specimen 1 and strain over the hole depth (specimen 1 / HDM / 1.4571).
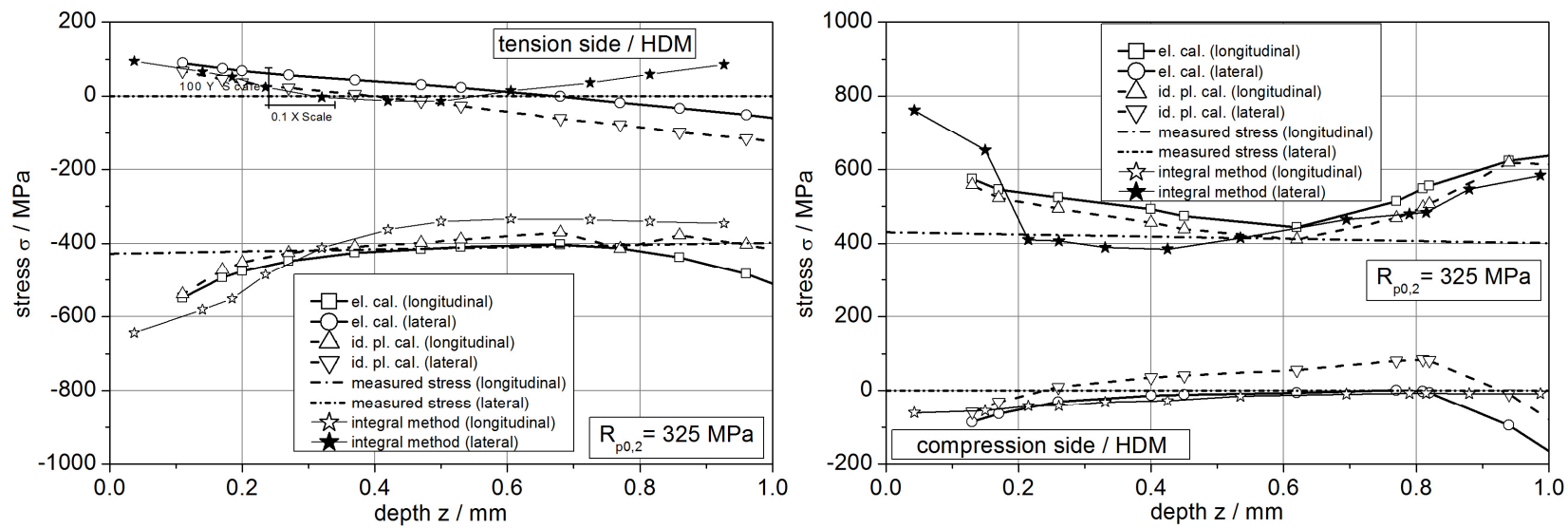

Fig. 4: Stresses (specimen 1/ HDM / 1.4571).
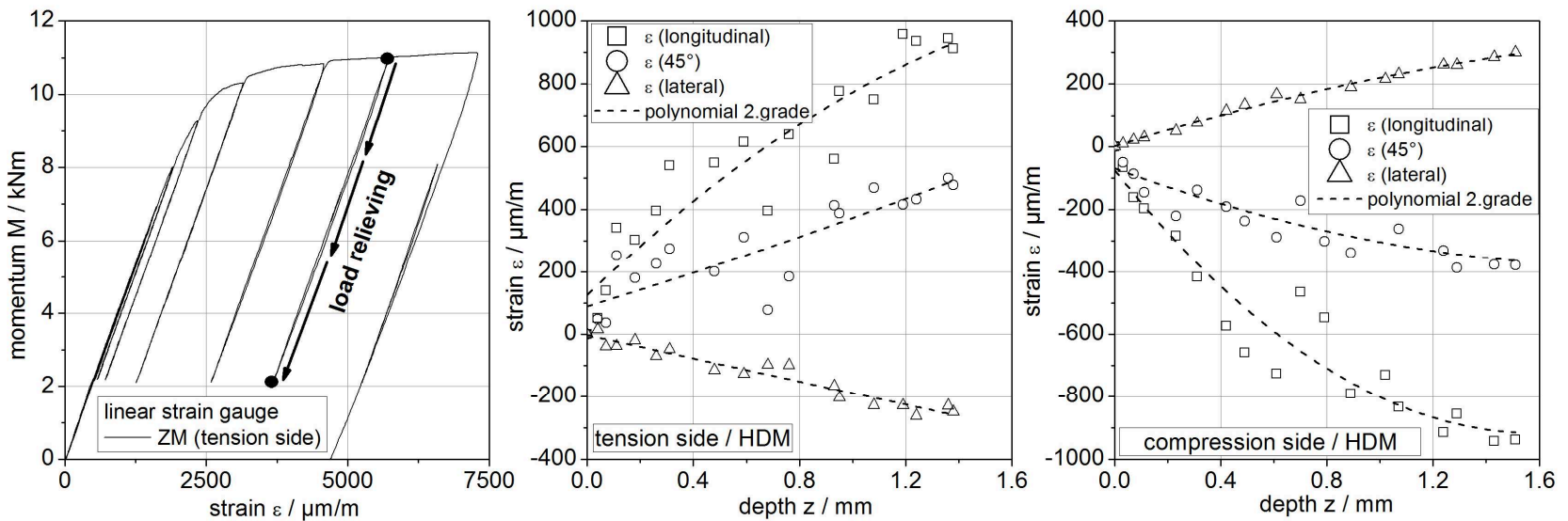

Fig. 5: Loading of specimen 2 and strain over the hole depth (specimen 2 / HDM / S355J2).
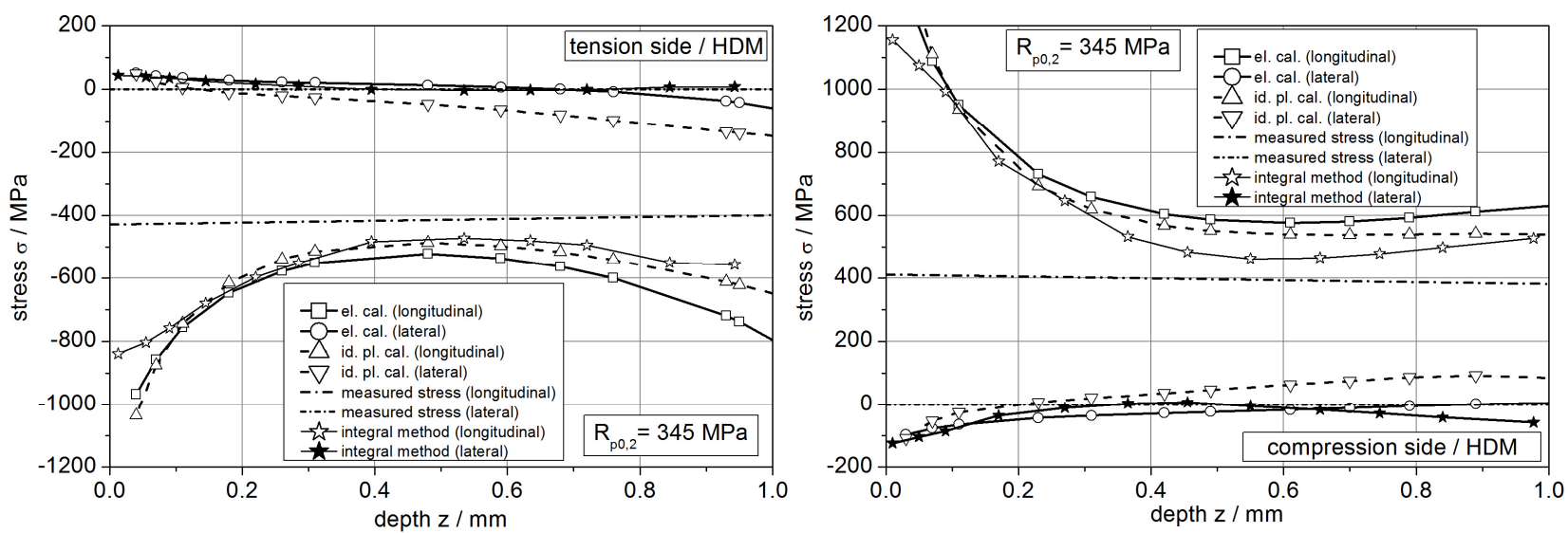

Fig. 6: Stresses (specimen 2 / HDM / S355J2). 

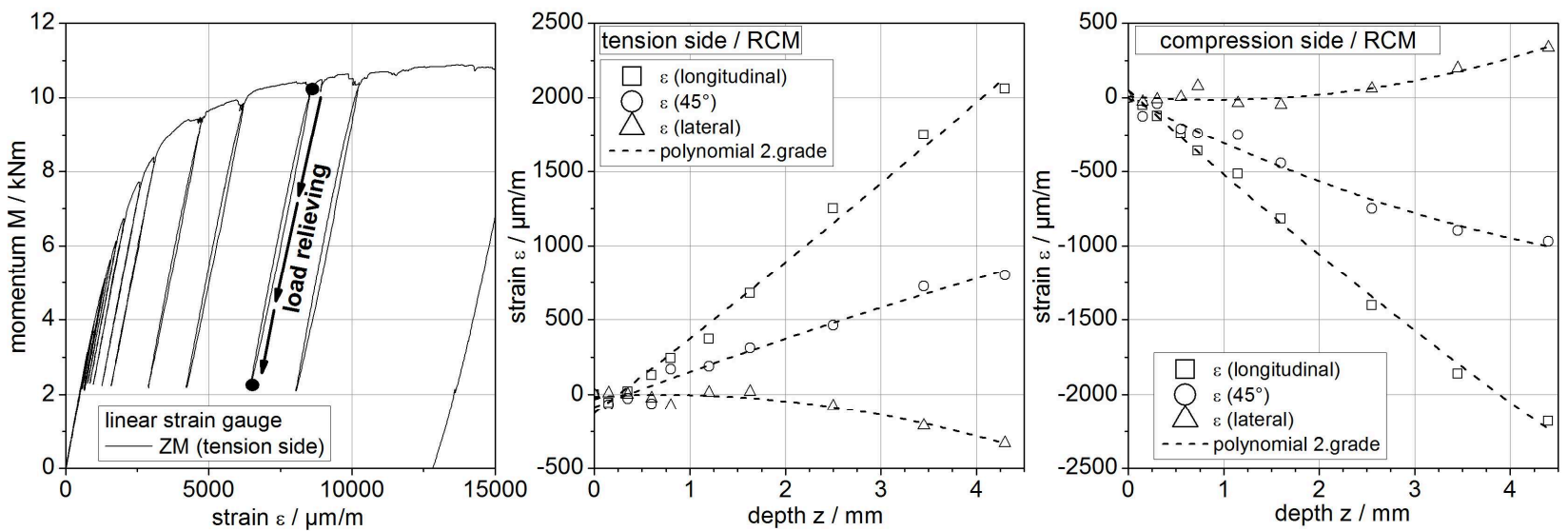

Fig. 7: Loading of specimen 3 and strain over the ring core depth (specimen 3 / RCM / 1.4571).
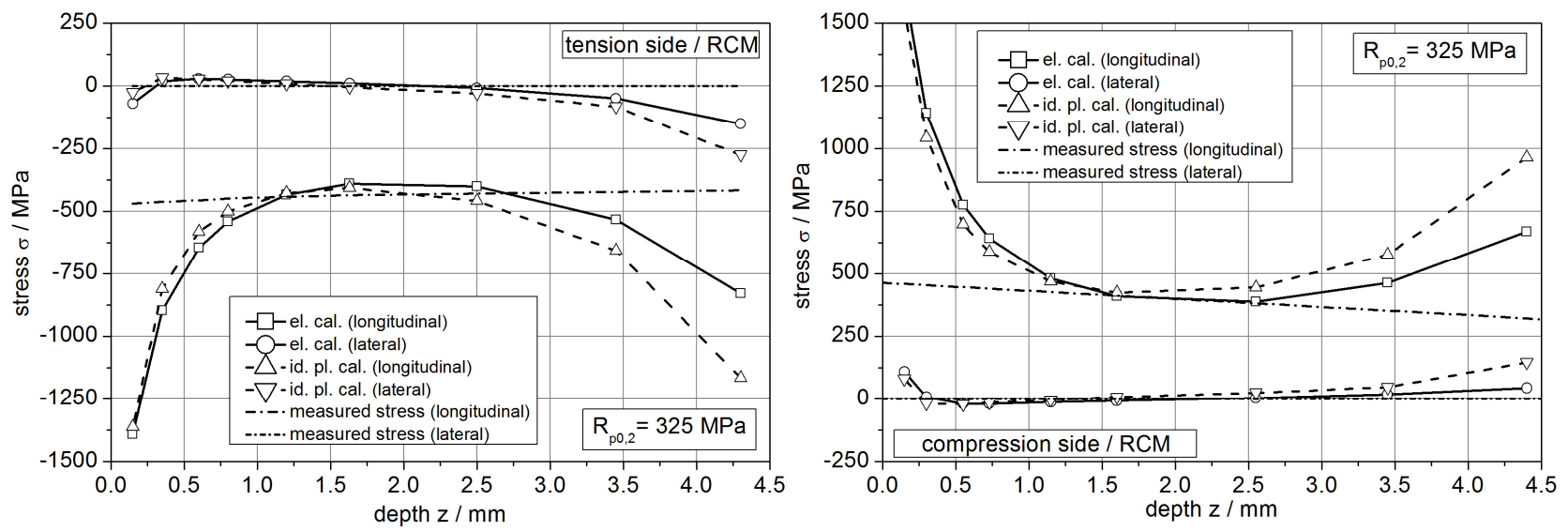

Fig. 8: Stresses (specimen 3 / RCM / 1.4571).
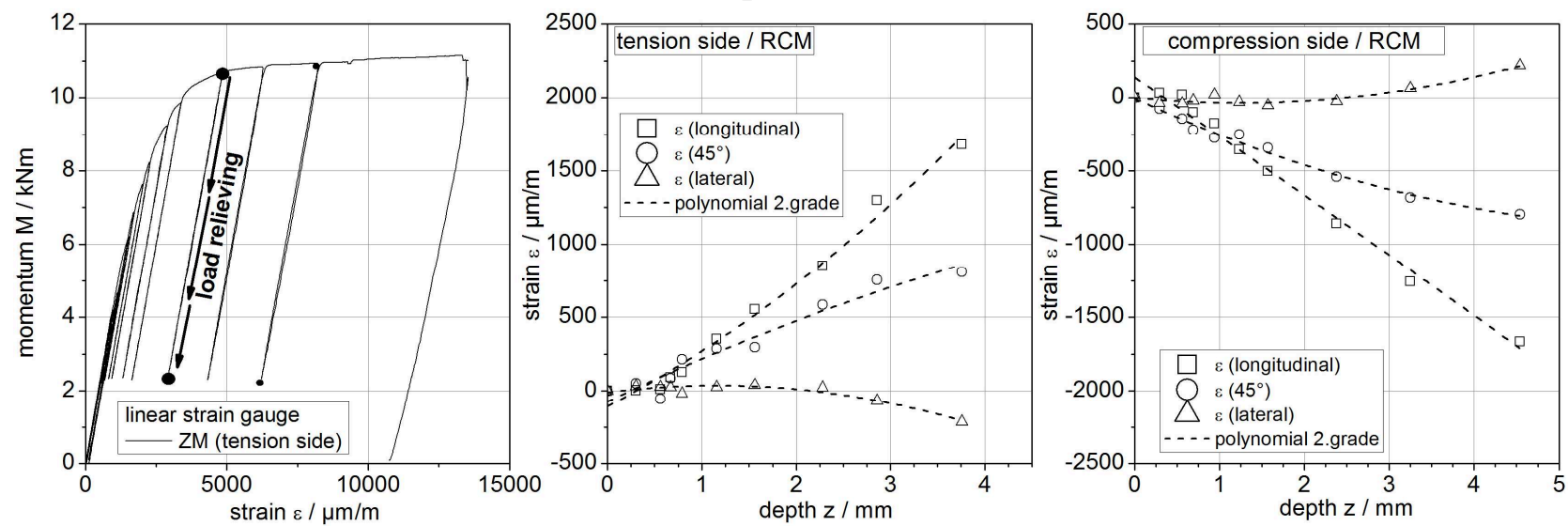

Fig. 9: Loading of specimen 4 and strain over the ring core depth (specimen 4 / RCM / S355J2).
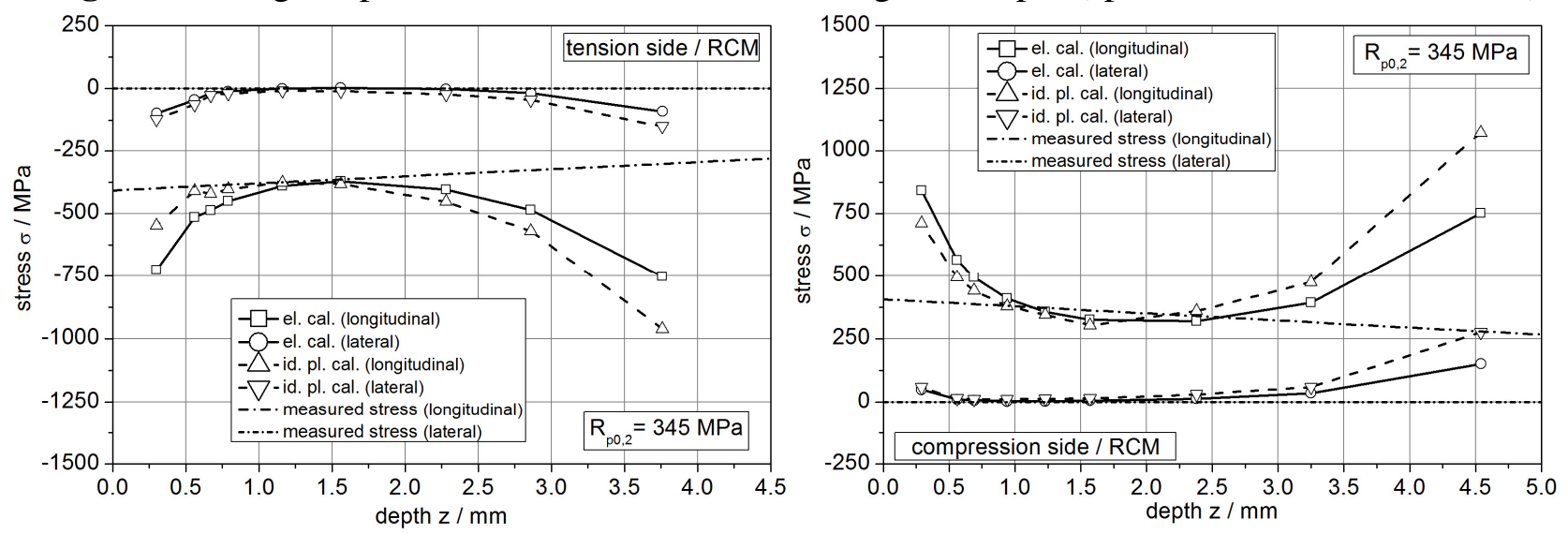

Fig. 10: Stresses (specimen 4 / RCM / S355J2). 
HDM: Relaxed measured strain scatter over the hole depth. Every measuring point on the specimen has its own measuring position $\mathrm{i}$ and hole depth. Every measuring point has one installed strain gauge rosette with little differences of application and every measuring point has one hole with practically differences of the diameter and eccentricity. The differences of the measuring points and to a limited extend the measuring accuracy of the measuring systems (force, strain and depth) cause the scattering of the measured strain over the hole depth. In reality it is complicated to repeat an HDM measurement exactly. This is the reason, that an approximation with polynomials has large differences, especially near the surface, to these scattered strain measurements over the hole depth. The calculated stresses should be next to the reference stresses (measured stresses). Especially near the surface and after a depth of $0,8 \mathrm{~mm}$ the deviations are quite large. These mistakes caused by the approximation of the strains and the sensitivity of the method in these depth areas. The elastic solutions (integral and differential method) are overrated at specimen 2. By using the method of adaptive calibration functions results has the right tendency, but other inertial defect sizes dominate. Mistakes by using the elastic calibration at high residual stresses are higher for a ferritic alloy than for an austenitic alloy. So the HDM works quite well between $0,2-0,8 \mathrm{~mm}$ and plastical effects can be taken into consideration within the method of adaptive calibration functions.

RCM: Variation of the measured strain by the RCM is much lower than of HDM. Every measuring point has one installed strain gauge rosette with little differences of application and every measuring point has one ring slot with practical differences of the diameters and eccentricity of the strain gauge rosette to the core centre. But the reproducibility of the measuring points for the RCM is better than the measuring points for the HDM. Eccentricity of the strain gauge rosette to the core centre causes only a slight difference of the relaxed strain, because the core relaxes homogenously over the core section. The RCM is in practice less sensitive to deviations of the application procedure. So reproducibility is simple. The calculated stresses should be next to the reference stresses (measured stresses). Near the surface and after a depth of 3,5 $\mathrm{mm}$ the deviations are large. These mistakes caused by the approximation of the strains and the sensitivity of the method in these depth areas. The elastic calculation produces good results, the method of adaptive calibration functions is not necessary. So the RCM works quite well between 1,0 - 3,5 mm and plastical effects can be neglected in mono-axial load cases.

\section{Acknowledgement}

The results presented are based on the BMWi Research Project 150 1423A "Enhancement of component safety by means of improved procedures for residual stress determination - consideration of elastic-plastic material properties" The author would like to express his thanks for the support and trust provided.

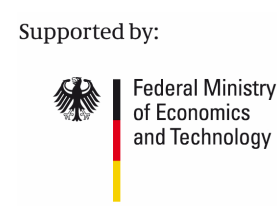

on the basis of a decision by the German Bundestag

\section{References}

[1] ASTM Standard E 837-08 (2008) "Standard Test Method for Determining Residual Stresses By The Hole-Drilling Strain-Gage Method".

[2] Gibmeier, J.; Kornmeier, M.; Scholtes, B. (2000) "Plastic deformation during application of the hole-drilling method" Materials Science Forum Vols. 347-349: S. 131-136.

[3] Kornmeier, M.; Nobre, J.; Gibmeier, J.; Scholtes, B; und Dias, A. (2000) "Plasticity effect on residual stress results using different hole-drilling evaluation methods"; ICRS6.

[4] Schwarz, T. (1996) „Beitrag zur Eigenspannungsermittlung an isotropen, anisotropen sowie inhomogenen, schichtweise aufgebauten Werkstoffen mittels der Bohrlochmethode und des Ringkernverfahrens" Dissertation Universität Stuttgart.

[5] von Mirbach, D. (2014) "Hole-drilling method for residual stress measurement - consideration of elastic-plastic material properties" Materials Science Forum Vols. 768-769: S. 174-181.

[6] Young, W. (2002) "Roak's formulas for stress and strain" (seventh edition) McGraw-Hill International Edition. 